EDITORIAL

\title{
Physiological Insights from Doppler Flow Patterns
}

\section{R Krishna Kumar}

How to cite this article: Kumar RK. Physiological Insights from Doppler Flow Patterns. J Perioper Echocardiogr 2013;1(2):39.

Source of support: Nil

Conflict of interest: None declared

Intraoperative echocardiography is traditionally viewed as a means to ascertain the adequacy of repair following congenital heart operations. Physiological assessment is traditionally limited to gross assessment of systolic ventricular function, right ventricular systolic pressures and identification of valvular regurgitation and measurement of flow gradients across outflow tracts.

Transesophageal echocardiography is a window to a wealth of physiological information that needs to be systematically exploited. Doppler flow patterns across the pulmonary veins are influenced by rhythm, respiration, left atrial compliance, state of the mitral valve and left ventricular systolic and diastolic function. In the presence of an atrial septal defect (ASD), the pulmonary flow the left to right shunt influences flow patterns in the pulmonary veins and which in turn is determined by relative compliance of the right $v s$ the left ventricle.

The preoperative pulmonary blood flow patterns described by the authors in the paper in this journal are consistent with a substantial left to right flow across the ASD. ${ }^{1}$ Two distinct preoperative flow patterns were seen. The small sample size does not allow further analysis. It is conceivable that there are important distinctions between the commonly seen pattern of indistinct systolic-diastolic waves and the less common pattern of a single systolic peak. The difference could be the result of different shunt size, age, and relative ventricular compliance and should perhaps be investigated in a larger series.

The changes in flow patterns after closure of the ASD is also of potential value. Following closure of ASD in adults a small proportion can develop substantial elevation in pulmonary venous pressure and this may result in pulmonary edema in a small minority. ${ }^{2,3}$ This is particularly dramatic following catheter-based closure of ASD in the older patient and occurs following extubation soon after closure of the defect. It is conceivable that the atrial reversal wave may be more prominent here. A very tall atrial reversal wave is likely to result from an elevated LV end diastolic pressure and should serve as a potential warning for the occurrence of pulmonary edema.

It is important to recognize that the patterns described here assume the presence of a sinus rhythm with a normal PR interval. Atrial flutter or junctional rhythm will dramatically change the pattern.

This paper could serve as a trigger for systematic exploration of pulmonary venous Doppler and AV valve flow patterns in a number of situations with meticulous comparison with preoperative physiology and postoperative outcomes in selected congenital heart defects. It is important to understand that Doppler flow patterns and velocities should be recorded in carefully standardized manner to allow consistent reproducibility. The field of perioperative echocardiography is a relatively new and it may be necessary to establish standard guidelines for recording Doppler flow patterns and velocities to allow comparison when recorded by different operators.

\section{REFERENCES}

1. Pulmonary venous Doppler flow profile before and after surgical closure of atrial septal defect in children. J Oper Echocardiogr.

2. Singhi AK, Mahesh K, Kumar RK. Pulmonary edema following transcatheter closure of atrial septal defect. Ann Pediatr Cardiol 2010;3:90-91.

3. Schubert S, Peters B, Abdul-Khaliq H, Nagdyman N, Lange $\mathrm{PE}$, Ewert P. Left ventricular conditioning in the elderly patient to prevent congestive heart failure after transcatheter closure of atrial septal defect. Catheter Cardiovasc Interv 2005;64:333-337.

\section{ABOUT THE AUTHOR}

\section{R Krishna Kumar}

Clinical Professor and Head, Department of Pediatric Cardiology Amrita Institute of Medical Sciences, Ponekkara, Cochin-682041, Kerala, India, Phone: 91-484-2853570, 91-9895092746, e-mail: rkrishnakumar@aims.amrita.edu,kumar_rk@yahoo.com 